\title{
Profound thrombocytopenia after primary exposure to eptifibatide
}

\author{
This article was published in the following Dove Press journal: \\ Drug, Healthcare and Patient Safety \\ 18 September 2010 \\ Number of times this article has been viewed
}

\author{
Nicholas B Norgard \\ Brian T Badgley \\ University at Buffalo, School of \\ Pharmacy and Pharmaceutical \\ Sciences, Buffalo, NY, USA
}

\begin{abstract}
Eptifibatide is a glycoprotein IIb/IIIa receptor antagonist used to reduce the incidence of ischemic events in patients with acute coronary syndromes and those undergoing percutaneous coronary intervention. A minority of patients given eptifibatide develop acute, profound thrombocytopenia $\left(<20,000\right.$ cells $\left./ \mathrm{mm}^{3}\right)$ within a few hours of receiving the drug. This case report discusses a patient who developed profound thrombocytopenia within hours of receiving eptifibatide for the first time. The Naranjo algorithm classified the likelihood that this patient's thrombocytopenia was related to eptifibatide as probable. Profound thrombocytopenia is an uncommon but clinically important complication of eptifibatide. This case report emphasizes the importance of monitoring platelet counts routinely at baseline and within 2-6 hours of eptifibatide administration.
\end{abstract}

Keywords: drug-induced thrombocytopenia, glycoprotein IIb/IIIa antagonists, eptifibatide, thrombocytopenia

\section{Introduction}

Eptifibatide is a glycoprotein IIb/IIIa inhibitor that blocks platelet aggregation by inhibiting the binding of fibrinogen to activated platelet glycoprotein IIb/IIIa receptors, thereby inhibiting platelet-platelet interaction and thrombus formation. Eptifibatide is part of the antithrombotic therapy used to prevent occlusion of the coronary arteries, thus reducing the incidence of ischemic events in patients with acute coronary syndromes and those undergoing percutaneous coronary intervention. ${ }^{1,2}$ While eptifibatide has significantly improved outcomes in patients undergoing percutaneous coronary intervention and among those presenting with an acute coronary syndrome, a small number of patients given eptifibatide develop acute profound thrombocytopenia $\left(<20,000\right.$ cells $\left./ \mathrm{mm}^{3}\right)$ within a few hours of receiving the drug that can increase the risk of serious bleeding and, in some rare cases, induce thrombosis. ${ }^{3-5}$ Profound thrombocytopenia is an uncommon but clinically important complication of glycoprotein IIb/IIIa inhibitors. This case report discusses a patient who developed profound thrombocytopenia within hours of first administration of eptifibatide.

\section{Case report}

A 42-year-old Caucasian female with no previous history of cardiovascular disease presented to the emergency department with a two-hour history of substernal chest pain that felt crushing in nature and radiated to the left arm and left jaw. Her past medical history included chronic back pain from a road traffic accident and an outpatient tubal ligation. She denied any previous history of blood dyscrasia or thrombocytopenia. 
She had smoked two packs of cigarettes per day for the last 28 years. Her family history was significant for her brother having had a stroke. She reported that she was not taking any medications prior to admission. Additionally, she denied any history of a previous hospitalization where she may have received heparin or eptifibatide.

At presentation, her electrocardiogram showed inferior and lateral ST elevation. Initial cardiac markers were creatine kinase (CK) 407 ng/mL (38-120 ng/mL), CK myoglobin (CK Mb) $2.5 \mathrm{ng} / \mathrm{mL}(0-3 \mathrm{ng} / \mathrm{mL})$, troponin $\mathrm{I}<0.05 \mathrm{ng} / \mathrm{mL}$ (0-0.02 ng/mL), and myoglobin $54 \mathrm{ng} / \mathrm{mL}(0-66 \mathrm{ng} / \mathrm{mL})$. Complete blood count obtained at the time of presentation included a white blood cell count of $8.9 \times 10^{9} / \mathrm{L}$ (normal range 4.1-10.9 × 10 $/ \mathrm{L})$, hemoglobin $14.3 \mathrm{~g} / \mathrm{dL}(12-15.2 \mathrm{~g} / \mathrm{dL}$ for women), hematocrit $41.6 \%$ (37\%-46\% for women), and platelet count $220 \times 10^{9} / \mathrm{L}\left(140-450 \times 10^{9} / \mathrm{L}\right)$. A complete metabolic panel drawn at the same time included serum creatinine $0.92 \mathrm{mg} / \mathrm{dL}$, glucose $148 \mathrm{mg} / \mathrm{dL}$ (70-100 mg/dL), and electrolytes were within normal limits.

The patient was initiated on aspirin $325 \mathrm{mg}$ po daily, lisinopril $5 \mathrm{mg}$ po daily, metoprolol succinate $50 \mathrm{mg}$ po daily, clopidogrel $300 \mathrm{mg} \times 1$ dose then $75 \mathrm{mg}$ po daily, an intravenous heparin infusion and atorvastatin $80 \mathrm{mg}$ po daily. Within 90 minutes of presentation, she was sent to the cardiac catheterization laboratory for primary percutaneous coronary intervention. Angiography revealed a 100\% distal-mid occlusion in the right coronary artery, a 40\%-50\% stenosis of the mid left anterior descending coronary artery, and a $75 \%$ stenosis of the mid circumflex artery. Before percutaneous coronary intervention, a double bolus of intravenous eptifibatide (180 $\mu \mathrm{g} / \mathrm{kg} 10$ minutes apart) was delivered followed by initiation of an eptifibatide infusion at $2 \mu \mathrm{g} / \mathrm{kg} / \mathrm{min}$. The patient also had the heparin infusion discontinued and received a $60 \mathrm{U} / \mathrm{kg}$ bolus heparin injection, resulting in an activated clotting time of 225 seconds. The patient then underwent successful stenting of the right coronary artery with a sirolimus-eluting stent. Once flow was restored, the patient became pain-free and had resolution of ST segment elevation. She was transferred in a stable condition to the coronary care unit for aggressive secondary prevention of her coronary artery disease. Post-percutaneous coronary intervention medications included aspirin $325 \mathrm{mg}$ po daily, lisinopril $5 \mathrm{mg}$ po daily, metoprolol succinate $50 \mathrm{mg}$ po daily, clopidogrel $75 \mathrm{mg}$ po daily, atorvastatin $80 \mathrm{mg}$ po daily, and the eptifibatide infusion was to be continued for 18 hours.

Approximately four hours post-percutaneous coronary intervention and eptifibatide initiation, the patient developed a precipitous thrombocytopenia, with her platelet count dropping by over $90 \%$ from baseline to $17 \times 10^{9} / \mathrm{L}$ (see Figure 1 ). A peripheral blood smear showed no signs of platelet clumping, ruling out pseudothrombocytopenia. The rest of her complete blood count at this time included hemoglobin $10.7 \mathrm{~g} / \mathrm{dL}$, hematocrit $31.3 \%$, and white blood cell count $6 \times 10^{9} /$ L. Eptifibatide was subsequently discontinued. The patient's platelet level reached its nadir $\left(13 \times 10^{9} / \mathrm{L}\right)$ approximately nine hours post-eptifibatide initiation. The patient's platelet count gradually climbed, and was $71 \times 10^{9} / \mathrm{L}$ at the time of discharge (approximately 80 hours post-eptifibatide initiation). The patient showed no signs of active bleeding, bruises, ecchymosis, or petechiae during the hospitalization.

One month later, the patient underwent elective percutaneous coronary intervention of her circumflex artery. Her platelet count at the time of the procedure was $142 \times 10^{9} / \mathrm{L}$. Bivalirudin was used during the percutaneous coronary intervention as an alternative to heparin and eptifibatide. She experienced no reductions in platelet count during the admission and was found to have a platelet count of $180 \times 10^{9} / \mathrm{L}$ at her two-month follow-up clinic visit.

\section{Discussion}

Drug-induced immune thrombocytopenia is an unpredictable and sometimes serious side effect of many medications, including heparin, quinine, nonsteroidal anti-inflammatory drugs, sulfonamides, and other antibiotics, especially vancomycin, rifampicin, and cephalosporins.${ }^{6,7}$ Platelet destruction is usually caused by drug-induced antibodies generated after drug exposure. The predominant pattern is an uneventful first exposure to a drug, then an acute drop in platelet count on re-exposure. Thrombocytopenia induced by the glycoprotein IIb/IIIa antagonist, eptifibatide, does not adhere to this pattern.

There are three clinically approved glycoprotein IIb/IIIa antagonists, ie, abciximab, eptifibatide, and tirofiban. These agents are similar in that they all inhibit platelet aggregation by blocking platelet-fibrinogen interaction via the glycoprotein IIb/IIIa receptor. Abciximab is associated with a higher incidence of thrombocytopenia than eptifibatide and tirofiban, and predominantly more often fits the usual pattern of drug-induced immune thrombocytopenia. ${ }^{8}$ Thrombocytopenia is seen in about $1 \%$ of patients given abciximab for the first time, while acute and more profound thrombocytopenia develops within a few hours in more than $10 \%$ of those treated a second time..$^{9-12}$ Abciximab is a Fab fragment of the chimeric human-murine monoclonal antibody $7 \mathrm{E} 3$ specific for $\beta 3$ integrin (glycoprotein IIIa). 


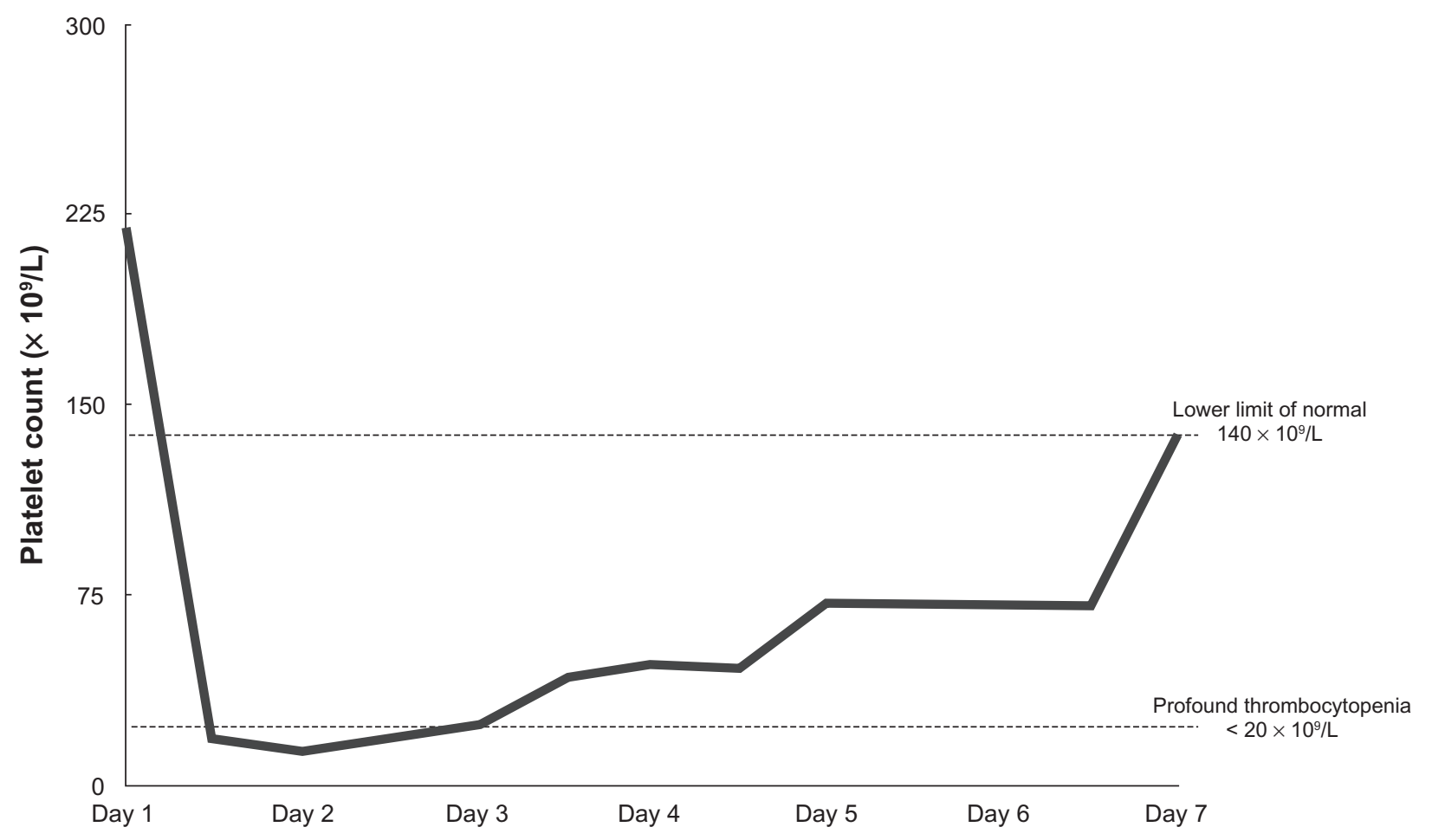

Figure I Timeline of platelet count during index hospitalization.

Most people in the healthy population have pre-existing antibodies to the human Fab portion of abciximab, although this does not appear to play a major role in thrombocytopenia. Patients who develop profound thrombocytopenia develop antibodies specific for the murine 7E3 fragment upon drug exposure. ${ }^{13,14}$ This explains the high incidence of profound thrombocytopenia on re-exposure to abciximab. Although most patients with abciximab-associated thrombocytopenia recover uneventfully, life-threatening bleeding, including intracranial hemorrhage, has been described. ${ }^{11,14}$

Eptifibatide is a ligand-mimetic drug that competitively inhibits the glycoprotein IIb/IIIa receptor. Eptifibatide binds specifically to the Arg-Gly-Asp recognition site on glycoprotein IIb/IIIa, thereby rendering the glycoprotein IIb/IIIa receptor incapable of binding fibrinogen. The incidence of acute profound thrombocytopenia with eptifibatide has been reported to be $0.2 \%-1.0 \%{ }^{1,2,15}$ As opposed to abciximab, patients may develop acute profound thrombocytopenia (platelet count $<20,000 / \mathrm{mm}^{3}$ ) upon primary exposure to eptifibatide. Of the 22 reported cases in the literature, only five patients had previous exposure to eptifibatide and three had exposure to abciximab. ${ }^{5}$ The binding of eptifibatide to the glycoprotein IIb/IIIa receptor may induce a conformational change in the receptor, creating ligand-induced binding sites. ${ }^{16}$ Some healthy individuals have strong naturally occurring antibodies that recognize these ligand-induced binding sites and are capable of having severe and sometimes life-threatening thrombocytopenia following drug administration. ${ }^{16}$ These antibodies can be identified in most patients' blood samples obtained prior to treatment with eptifibatide, affirming that they can be naturally occurring. ${ }^{16} \mathrm{~A}$ variety of assays have been used to show that most patients developing thrombocytopenia after eptifibatide administration have antibodies that recognize glycoprotein IIb/IIIa occupied by the drug. ${ }^{16-18}$ On the other hand, patients who receive eptifibatide and do not have antibodies of this type do not experience profound thrombocytopenia. ${ }^{16}$ Because thrombocytopenia in patients who have received eptifibatide is usually caused by pre-existing antibodies, pretreatment screening for pre-existing antibodies has been proposed to reduce the incidence of eptifibatide-induced thrombocytopenia, but improvements in antibody detection are needed before this practice becomes routine. ${ }^{17}$

Treatment with glycoprotein IIb/IIIa antagonists has also been associated with pseudothrombocytopenia, an artifactual finding suspected initially by finding platelet clumping on a blood smear. ${ }^{19}$ It has been shown to account for over one-third of cases of thrombocytopenia during glycoprotein IIb/IIIa inhibitor therapy. ${ }^{19}$ It is of no clinical relevance, but must be ruled out so that glycoprotein IIb/IIIa antagonist therapy 
is not unnecessarily discontinued. Pseudothrombocytopenia was ruled out in this patient because there was no platelet clumping observed on peripheral blood smear.

The patient in this report was exposed to several agents during her admission that have been associated with profound thrombocytopenia. Heparin is well known to precipitate thrombocytopenia, but the published literature to date suggests that a previous exposure is required, similar to the reaction seen with heparin-induced thrombocytopenia. ${ }^{20}$ Heparin-induced thrombocytopenia type I is characterized by a mild and transient asymptomatic thrombocytopenia (rarely $<100,000$ platelets $/ \mathrm{mm}^{3}$ ) that develops early (usually within the first two days of starting heparin). ${ }^{20}$ Heparin-induced thrombocytopenia type II is immune-mediated and associated with a risk of thrombosis. In patients receiving heparin for the first time, the onset of thrombocytopenia usually occurs 5-10 days after the administration of the heparin. ${ }^{20}$ The platelet drop can be seen within hours in patients with pre-existing heparin/platelet factor 4 antibodies from a previous exposure. ${ }^{20}$ Our patient's drop in platelet count was more severe than would be expected with heparin-induced thrombocytopenia type I. Additionally, the patient had no previous exposure to heparin and the timeframe of the decline in platelets does not fit heparin-induced thrombocytopenia type II. This makes it difficult to attribute our patient's thrombocytopenia to heparin and, due to a low clinical suspicion of heparin-induced thrombocytopenia, serologic tests were not performed.

Thrombotic thrombocytopenic purpura can occur after the initiation of clopidogrel therapy, often within the first two weeks of treatment. ${ }^{21}$ Clopidogrel-induced thrombotic thrombocytopenic purpura is characterized by the presence of microangiopathic hemolytic anemia, thrombocytopenia, fever, neurologic manifestations, and renal insufficiency. ${ }^{21}$ Other than thrombocytopenia, our patient did not manifest any of the hallmarks of thrombotic thrombocytopenic purpura and only received one $300 \mathrm{mg}$ dose of clopidogrel six hours before the observed drop in platelet count. It is unlikely that clopidogrel played a role in the development of thrombocytopenia in our patient.

The Naranjo algorithm classified the likelihood that the thrombocytopenia was related to eptifibatide as probable. ${ }^{22}$ Naranjo scores with heparin and clopidogrel were 1 , indicating that these agents were possible, but most likely doubtful, causes of thrombocytopenia in this patient. $^{22}$

\section{Conclusion}

Profound thrombocytopenia is an uncommon but clinically important complication of eptifibatide. Thrombocytopenia occurring after first exposure to eptifibatide appears to be explained by the fact that antibodies are naturally present in some individuals. Assays for pretreatment screening for preexisting antibodies are available, but are not yet established for regular use. This case report emphasizes the importance of monitoring platelet counts routinely at baseline and within 2-6 hours of eptifibatide administration.

\section{Disclosure}

The authors report no conflicts of interest in this work.

\section{References}

1. Inhibition of platelet glycoprotein IIb/IIIa with eptifibatide in patients with acute coronary syndromes. The PURSUIT Trial Investigators. Platelet Glycoprotein IIb/IIIa in unstable angina: Receptor suppression using integrilin therapy. N Engl J Med. 1998;339(7):436-443.

2. Novel dosing regimen of eptifibatide in planned coronary stent implantation (ESPRIT): A randomised, placebo-controlled trial. Lancet. 2000;356(9247):2037-2044.

3. McClure MW, Berkowitz SD, Sparapani R, et al. Clinical significance of thrombocytopenia during a non-ST-elevation acute coronary syndrome. The platelet glycoprotein IIb/IIIa in unstable angina: Receptor suppression using integrilin therapy (PURSUIT) trial experience. Circulation. 1999;99(22):2892-2900.

4. Gao C, Boylan B, Bougie D, et al. Eptifibatide-induced thrombocytopenia and thrombosis in humans require FcgammaRIIa and the integrin beta3 cytoplasmic domain. J Clin Invest. 2009;119(3):504-511.

5. Russell KN, Schnabel JG, Rochetto RP, Tanner MC. Acute profound thrombocytopenia associated with readministration of eptifibatide: Case report and review of the literature. Pharmacotherapy. 2009;29(7): 867-874.

6. Rizvi MA, Kojouri K, George JN. Drug-induced thrombocytopenia: An updated systematic review. Ann Intern Med. 2001;134(4):346.

7. Aster RH. Drug-induced immune thrombocytopenia: An overview of pathogenesis. Semin Hematol. 1999;36 Suppl 1:2-6.

8. Dasgupta H, Blankenship JC, Wood GC, Frey CM, Demko SL, Menapace FJ. Thrombocytopenia complicating treatment with intravenous glycoprotein IIb/IIIa receptor inhibitors: A pooled analysis. Am Heart J. 2000;140(2):206-211.

9. Ferguson JJ, Kereiakes DJ, Adgey AA, et al. Safe use of platelet GP IIb/IIIa inhibitors. Eur Heart J. 1998;19 Suppl D:40-51.

10. Madan M, Kereiakes DJ, Hermiller JB, et al. Efficacy of abciximab readministration in coronary intervention. Am J Cardiol. 2000;85(4): 435-440.

11. Vahdat B, Canavy I, Fourcade L, et al. Fatal cerebral hemorrhage and severe thrombocytopenia during abciximab treatment. Catheter Cardiovasc Interv. 2000;49(2):177-180.

12. Tcheng JE, Kereiakes DJ, Lincoff AM, et al. Abciximab readministration: Results of the ReoPro Readministration Registry. Circulation. 2001;104(8):870-875.

13. Curtis BR, Divgi A, Garritty M, Aster RH. Delayed thrombocytopenia after treatment with abciximab: A distinct clinical entity associated with the immune response to the drug. J Thromb Haemost. 2004;2(6):985-992.

14. Curtis BR, Swyers J, Divgi A, McFarland JG, Aster RH. Thrombocytopenia after second exposure to abciximab is caused by antibodies that recognize abciximab-coated platelets. Blood. 2002;99(6):2054-2059. 
15. Hongo RH, Brent BN. Association of eptifibatide and acute profound thrombocytopenia. Am J Cardiol. 2001;88(4):428-431.

16. Bougie DW, Wilker PR, Wuitschick ED, et al. Acute thrombocytopenia after treatment with tirofiban or eptifibatide is associated with antibodies specific for ligand-occupied GPIIb/IIIa. Blood. 2002;100(6): 2071-2076.

17. Billheimer JT, Dicker IB, Wynn R, et al. Evidence that thrombocytopenia observed in humans treated with orally bioavailable glycoprotein IIb/IIIa antagonists is immune mediated. Blood. 2002;99(10):3540-3546.

18. Aster RH, Curtis BR, Bougie DW, et al. Thrombocytopenia associated with the use of GPIIb/IIIa inhibitors: Position paper of the ISTH working group on thrombocytopenia and GPIIb/IIIa inhibitors. $J$ Thromb Haemost. 2006;4(3):678-679.
19. Sane DC, Damaraju LV, Topol EJ, et al. Occurrence and clinical significance of pseudothrombocytopenia during abciximab therapy. J Am Coll Cardiol. 2000;36(1):75-83.

20. Warkentin TE, Greinacher A. Heparin-induced thrombocytopenia: Recognition, treatment, and prevention. The Seventh ACCP Conference on Antithrombotic and Thrombolytic Therapy. Chest. 2004;126 Suppl 3: 311S-337S,

21. Bennett CL, Connors JM, Carwile JM, et al. Thrombotic thrombocytopenic purpura associated with clopidogrel. $N$ Engl J Med. 2000; 342(24): 1773-1777.

22. Naranjo CA, Busto U, Sellers EM, et al. A method for estimating the probability of adverse drug reactions. Clin Pharmacol Ther. 1981;30(2): $239-245$.

\section{Publish your work in this journal}

Drug, Healthcare and Patient Safety is an international, peer-reviewed open-access journal exploring patient safety issues in the healthcare continuum from diagnostic and screening interventions through to treatment, drug therapy and surgery. The journal is characterized by the rapic reporting of reviews, original research, clinical, epidemiological and

\section{Dovepress}

post-marketing surveillance studies, risk management, health literacy and educational programs across all areas of healthcare delivery. The manuscript management system is completely online and includes a very quick and fair peer-review system. Visit http://www.dovepress.com/ testimonials.php to read real quotes from published authors.

Submit your manuscript here: http://www.dovepress.com/drug-healthcare-and-patient-safety-journal 